\title{
CONSIDERATIONS ON THE NECESSITY OF MODERNIZATION OF ENGINEER FORCES FROM NATO MEMBERS COUNTRIES
}

\author{
Mircea VLADU, Ioan- Dan POPA \\ "Nicolae Bălcescu" Land Forces Academy, Sibiu, Romania \\ vladumircea57@yahoo.com, paragon1971@gmail.com
}

\begin{abstract}
The engineer branch has been established at a certain stage of historical evolution of the armed forces to provide engineer support to the combat forces, as well as to support civil societies to achieve, develop and maintain the necessary infrastructure elements in order to conduct of economic and social activities. Having in mind all these elements and taking into account the structural perspective and the endowment, the evolution of engineer forces should have been made in accordance with the evolution of the common combat joint forces, keeping the same rhythm of development. Unfortunately, the engineer forces within the armies of the NATO member states did not evolve under the aforementioned aspects, even if some commitments have been made at the various summits held over time at different levels.

As a result of these realities, in this paper we present some considerations about what should be the way ahead in the evolution of the engineer forces until the horizon of 2050.
\end{abstract}

Keywords: engineer forces; engineer support; modernization; multi-purpose engineer vehicle

\section{Introduction}

Taking into account our careers held at different levels of engineer forces, we had the opportunity to participate in multinational exercises and missions in which engineer structures from member and non-NATO armies evolved, every time expressing our satisfaction related to high level of mobility of the combat forces, generated by supple structures, endowed with powerful means and systems of hitting and, on the other hand, we were discouraged by the engineer entities with weak limited organizational structure, endowment and mobility which are not able to provide the engineer support to combat forces at the standards required by the joint operations.

The existence of some limitations at organizational and endowment level have influenced the action of engineer forces that are unable to provide support for the mobility, counter-mobility and survivability of their own combat forces, to thwart / restrict / hinder the mobility of enemy forces, to contribute to the maintenance of the operational capacity of friendly forces or to participate in general engineer support.

These gaps and limitations have been recorded and continue to be recorded as allied army doctrines stipulate that engineer forces are capable of fulfilling the missions and tasks of engineer support in the combined operations with the multi-purpose engineer technique currently provided only on paper, because of the austerity budgets of some countries.

Under these circumstances, we ask some rhetorical questions, as follows:

Why doctrines of engineer support and combat manuals do not provide for the fulfillment of missions, the level of 
endowment and instruction existing at one time, instead of level described in major endowment plans, which because of the austerity budgets cannot be operationalized?

Why we have established a high level of ambition in relation with engineer forces which cannot be reached considering the actual organizational structure, endowment, training, resources etc.?

Someone might answer that the future needs to be built, and there is a need for normative acts to legislate on this construction. If the approach would be in this way it could be accepted but not in terms of the form empty of content.

From this perspective, we believe that engineer forces, in order to be able to carry out missions of engineer support in a timely and efficient manner need to be deeply restructured in terms of organization, endowment, instruction, etc., so that in the integrated battle space, doctrinal provisions and regulations have real support, as is the case with the combat forces during the joint operations, protection etc.

\section{Considerations regarding the evolution of the engineer forces up to the horizon of 2050}

We assume that the evolution of engineer endowment by 2050 must be addressed in terms of the possibilities of fulfilling missions and tasks of engineer support in favor of mobility, counter-mobility, maintenance of operational capability, and general engineer support in joint operations. Considering the proposed horizon, one might ask: Why we set a far-off time horizon? The answer can be very simple: the discrepancy between the doctrinal provisions, the regulations, the fighting manuals, on one hand, and the organizational structure, the endowment and the training of the engineer forces, on the other hand, is huge, so we consider that it would take $30-40$ years for its substantial diminishing, in the conditions that would be allocated considerable budgets.
In this perspective, we consider that in order to ensure the mobility of our own combat forces in the joint operations, it is necessary to design and build a polyvalent armored engineer machine/multi- purpose engineer vehicle, provided with different equipment, designated to replace the old and rudimentary machines which, unfortunately, are still in use.

This versatile armored engineer machine with its working equipment can also replace the old engineer machines that were designed to remove, reduce, mark and bypass or cross natural obstacles, explosive and non-explosive obstacles, and so on. At the same time, this armored engineer machine could also be used for the arrangement, maintenance, reconstruction and construction of the roads, the arrangement of the entrances and exits at the crossing points for tactical displacements etc. For the passing of forces across the water courses, it is required to get rid of the classical pontoon bridges, very difficult to maneuver from one area to another, to build bridges and gates, to ensure concealment against observation of all kinds executed by the enemy etc. Will be necessary to design and construct a submersible pontoon machine, the bridge being based on the width of the water course in a number of submersible pontoons coupled to each other by both mechanical and hydraulic devices. The construction and use of the submersible pontoon machine would reduce the maneuver time from one watercourse to another and the bridgedismounting. At the same time, it would provide $100 \%$ concealment, thus protecting it against all kinds of enemy reconnaissance. The passing of joint forces across dry valleys with the widest width, muddy watercourses with a shallow depth could be achieved in a shorter and safer time if will be designed and constructed metal bridges with hydraulic infrastructure.

In this respect, metal bridges with openings of no more than 10 meter each could be built, with hydraulic pillars whose height 
could vary between $2.5-5 \mathrm{~m}$. By endowment of engineer forces with metal bridges with hydraulic infrastructure, the following advantages could be achieved:

a) reducing the time for mounting and dismantling the bridge;

b) ensuring that large amounts of water, sewers and ice built, floods formed from alluvial materials formed during floods;

c) the impossibility of destroying the bridge by arson;

d) use of hydraulic beams and piles when needed for the construction of superstructures for temporary storage of materials for land forces.

To prevent the mobility of enemy forces, it would not be too costly to design and construct a motor-functional armored engineer vehicle, designate to execute in a short and safe way, the following:

a) non-explosive obstacles for the protection of forces and removal of those executed by the enemy;

b) strengthening of artificial obstacles;

c) reconstruction of natural barriers in order

to increase their value;

d) mechanical destruction of infrastructure elements;

e) execution of the tranches and the ditches of communication, etc.

In order to maintain the operational capacity of our own forces during the deep operations, we consider that it would be necessary to design and build the sheltered armored vehicle, with technical possibilities for preparing the infrastructure for its location at short notice and safe. Under these circumstances, different command posts will be obtained of a number of sheltered armored vehicles, each one having a specific role in this puzzle.

By designing and constructing of the sheltered armored vehicle, could be accomplished the following:

a) short-time installation of the command post in the field;

b) ensuring optimal conditions of protection, work, rest and feeding of the personnel serving the command point; c) appropriate concealment of the location of the command post;

d) maneuver of the command post in the rhythm of execution of the combined operations.

At the same time, we consider beneficial to constitute during the force generation process, a Joint Fortification Mobile Detachment, using personnel and specific equipment which belong to engineer forces, as well as personnel with military obligations from civilian contractors and a specific equipment provided by civilian contractors.

The engineer general support could be significantly improved by designing and constructing following capabilities:

a) water well drilling installations up to a depth of more than 2,000 feet, where the level of nitrates and nitrites is much lower;

b) installations for potable water with higher productivity of 200,000 liters/day;

c) $150 \mathrm{KVA}$ armored vehicle for supplying the electrical power necessary for the operation of the command posts, the timber and concrete factories.

Drilling and water-borne installations could be part of Joint Mobile Water Detachment, which could be activated during force generation process, following the same procedure as Joint Fortification Mobile Detachment.

\section{Conclusions}

The future Joint Operations will have a much changed physiognomy comparing to present, as in the endowment of the combat forces will be new categories of powerful surgical instruments and systems.

In order to carry out their planned missions, they need specialized and efficient support from engineer forces that can only be given if the engineer forces are subjected, in the next 30-40 years, to a profound restructuring process under the doctrinal, structural, endowment, training, etc.

This process requires significant investments, but at completion we will be able to see the existence of powerful 
engineer forces capable of providing engineer support for the forces groups meeting the prescriptions and standards of doctrines, regulations and combat manuals. There is a bulk of military strategists who claimed that to engineer forces were not given due attention and remained at the development level of the 70-80s in terms of endowment, mainly due to the lack of resources and new technologies in the engineer field..

Having an optimistic approach and based on allocation of minimum $2 \%$ of GDP for army modernization, the engineer forces will be able to keep the same rhythm of development as common combat joint forces.

\section{References}

[1] Doctrine of engineer forces in joint operations, Edition 2016;

[2] Col. assoc. prof. Mircea Vladu, $\mathrm{PhD}$ and collective, Endowment of engineer according to the challenges of future war, National Defense University "Carol I " Publishing House, Bucharest, 2006. 